\title{
A Randomized Controlled Trial of a Self-Regulation Intervention for Older Adults with Asthma
}

\author{
Alan P. Baptist, MD, MPH, ${ }^{* \dagger}$ Jacqueline A. Ross, MD, ${ }^{*}$ Ye Yang, MS, ${ }^{\dagger}$ Peter X. K. Song, PhD, ${ }^{\dagger *}$ \\ and Noreen M. Clark, PhD ${ }^{\dagger}$
}

OBJECTIVES: To evaluate a self-regulation intervention for asthma for older adults.

DESIGN: A blinded randomized controlled trial.

SETTING: Single-center tertiary care academic center.

PARTICIPANTS: Seventy older adults aged 65 and older with persistent asthma randomized to an intervention or control group.

INTERVENTION: Participants participate in a six-session program conducted over the telephone and in group sessions. Participants selected an asthma-specific goal, identified problems, and addressed potential barriers.

MEASUREMENTS: Outcomes were assessed at 1, 6, and 12 months and included the mini-Asthma Quality of Life Questionnaire (mAQLQ), Asthma Control Questionnaire (ACQ), healthcare utilization, exhaled nitric oxide (FENO), and percentage of predicted forced expiratory volume in 1 second (FEV1\%).

RESULTS: The mAQLQ score was significantly higher in the intervention group at 1,6 , and 12 months, even after controlling for confounding factors. The between-group difference decreased over time, although at 12 months, it remained greater than 0.5 points. The ACQ was better in the intervention group than in the control group at 1, 6, and 12 months. At 12 months, those in the intervention group were 4.2 times as likely as those in the control group to have an ACQ score in the controlled range. Healthcare utilization was lower in the intervention group, although no difference was observed in FENO or predicted FEV1\%.

CONCLUSION: A self-regulation intervention can improve asthma control, quality of life, and healthcare utilization in older adults. J Am Geriatr Soc 61:747-753, 2013.

Key words: asthma; self-regulation; older adults; quality of life; healthcare utilization

From the *Department of Internal Medicine, School of Medicine, ${ }^{\dagger}$ Center for Managing Chronic Disease and ${ }^{\star}$ Department of Biostatistics, School of Public Health, University of Michigan, Ann Arbor, Michigan.

Address correspondence to Dr. Alan P. Baptist, 24 Frank Lloyd Wright Drive, Suite H-2100, Ann Arbor, MI 48106. E-mail: abaptist@med.umich. edu

DOI: 10.1111 /jgs.12218

A sthma has frequently been overlooked in older adults. Physicians and patients often erroneously believe that asthma is a disease that affects only children or that all asthma begins in childhood, but studies show that up to $40 \%$ of adults with asthma have their first attack after the age of $40 .{ }^{1,2}$ Underdiagnosis and delayed initiation of care for asthma is common and can have dire consequences in elderly adults. ${ }^{3-5}$ In the United States, the most recent data shows that the asthma hospitalization rate for individuals aged 65 and older is 237 per 100,000, which is the second highest for any age group and only slightly less than the rate for those younger than 15 (239 per 100,000). ${ }^{6}$ The length of asthma hospitalizations was by far highest in persons aged 65 and older, with an average of 4.5 days.

Although there have been more-dramatic decreases in asthma mortality in younger individuals than in older adults, the rates for older adults with asthma have only recently plateaued. ${ }^{7,8}$ In the United States, individuals aged 65 and older have the highest asthma mortality of any age group, accounting for more than $50 \%$ of all asthma deaths. ${ }^{7,9,10}$ There are also significant concerns that asthma mortality based on death certificate data underestimate the true number of deaths in elderly adults, because comorbidities may mask the true cause of death. ${ }^{11}$

Older adults with asthma have a disproportionate level of morbidity and mortality related to the disease, but little research has focused on optimal treatment and diagnostic strategies in this population, ${ }^{12}$ and many asthma trials have excluded potential subjects aged 65 and older. ${ }^{13-16}$ As the population of the United States ages, it is expected that the number of older adults with asthma will more than double, to nearly 5 million by $2,030 .^{7}$ Therefore, novel approaches are necessary to improve the care of this population.

A leading theory as to why asthma morbidity and mortality have remained unacceptably high in older adults is that the current diagnostic, therapeutic, and educational approaches do not address the unique challenges this age group faces. ${ }^{17}$ One approach to address these challenges would be through an individualized self-regulation 
program. The self-regulation theory postulates that individuals must be invested in specific outcomes of personal importance to enact meaningful behavioral change, regardless of how sound the medical advice may be. ${ }^{18}$ Through the self-regulatory process, individuals are able to observe and learn from their experience and determine methods for changing behavior, improving multiple health outcomes, but there have been few studies examining self-regulation as a method to improve health outcomes in elderly adults, and its efficacy in this population is unclear.

The purpose of this study was to evaluate an asthma self-regulation intervention for older adults, specifically observing the effects on asthma quality of life (QoL) and asthma control.

\section{MATERIALS AND METHODS}

\section{Study Design}

A randomized, double-blind, controlled trial was conducted with patients from the University of Michigan Health System who met the study criteria. All patients provided written informed consent for participation in the clinical trial. The trial was registered at www.clinicaltrials.gov (NCT00941694). Eligible participants were randomized in a 1:1 ratio to the intervention and control groups using a random number generator. After enrollment, all participants received standard asthma education administered by a health educator. Topics included proper inhaler technique, common asthma triggers, assessment of asthma control, and signs of an asthma exacerbation. All participants were also provided the American College of Chest Physicians Controlling Your Asthma patient education guide. ${ }^{19}$ An allergist called participants randomized to the control group 1 and 2 weeks after enrollment to address any inquires regarding information received during the asthma education session.

At enrollment, all participants completed a basic health questionnaire, along with asthma-specific information, spirometric evaluation, fraction of exhaled nitric oxide level (FENO) (measured using the NIOX MINO, Aerocrine Inc., New Providence, NJ), and allergy skin testing for evaluation of atopy (using the Multi-Test II, Lincoln Diagnostics, Decatur, IL) to a battery of allergens, including tree mix, weed mix, grass mix, mold mix, dog, cat, dust mite, and cockroach. Asthma severity was based upon daily controller medication use. Asthma severity of participants who required an inhaled corticosteroid (ICS) or leukotriene receptor antagonist (LTRA) as monotherapy was considered mild, of those who required an ICS along with one additional daily controller medication (LTRA, long-acting beta agonist, theophylline, or anticholinergic medication) was considered moderate, and of those requiring daily oral corticosteroids or an ICS with two additional controller medications was considered severe.

\section{Participants}

Eligible participants were outpatients aged 65 and older with a current physician diagnosis of asthma. All participants were currently using a daily controller medication for asthma and had access to a home telephone. Participants were excluded if they had a diagnosis of chronic obstructive pulmonary disease (COPD) or any other primary pulmonary disorder, were current smokers, had a smoking history of longer than 20 pack-years (to exclude individuals with likely COPD), ${ }^{20}$ or had mental impairment that would preclude participation in an asthma selfmanagement program. All participants provided written informed consent, and their primary care physicians approved enrollment before randomization. Participants and their physicians were blinded to group assignment. The institutional review board at the University of Michigan approved the study.

\section{Intervention}

After enrollment, participants randomized to the intervention group were separated into cohorts of approximately seven individuals and completed a 6-week asthma intervention based on the social cognitive theory of behavioral change. The intervention consisted of three in-person group sessions and three one-on-one telephone sessions. Group sessions included seven participants and a health educator who served as the leader. A health educator who had received a 2-day training session at the University of Michigan Center for Managing Chronic Diseases on the principles of self-regulation and the basics of asthma management conducted all group and telephone sessions.

The personalized intervention followed a self-regulation process in which participants selected a specific asthma-related problem they would like to address, observed and researched their routine to see how asthma was preventing resolution of this problem, and identified and developed a plan to achieve this objective. Each step of the intervention was self-directed, with personalized assistance from the health educator. The final step of the intervention focused on teaching participants how to manage asthma problems that might arise in the future. A more-detailed description of the specific intervention sessions can be found in the online supplemental repository, along with common problems addressed (Table S1) and barriers identified (Table S2). During the observation phase, participants were provided with a peak flow meter and asked to monitor peak flow readings along with asthma symptoms over a 2 -week period. The study team did not recommend any specific medication changes.

\section{Measures and Data Collection}

Intervention and control subjects were grouped into cohorts of approximately 14 individuals ( 7 intervention and 7 control) for purposes of a matched follow-up schedule. The baseline time point for both groups was 6 weeks after enrollment in the study to allow the intervention group to complete the self-regulation intervention. The primary outcome was asthma QoL as assessed according to mini-Asthma Quality of Life Questionnaire (mAQLQ) score assessed at 1, 6, and 12 months, after adjustment for baseline AQLQ score, age, sex, body mass index (BMI), asthma severity, presence of atopy (skin test reactivity to any allergen), baseline percentage of predicted forced expiratory volume in 1 second (FEV1\%), and years of asthma. The mAQLQ is a 15-item, 7-point scale addressing four domains specific to individuals with asthma: activity limi- 
tations, symptoms, emotional function, and environmental stimuli. ${ }^{21}$ It can be used to measure change over time and has been commonly used in asthma studies. The minimally clinically significant difference for AQLQ scores has been defined as 0.5 points. $^{22}$

Secondary outcomes included asthma control as measured using the Asthma Control Questionnaire (ACQ). ${ }^{23}$ The ACQ is a validated, 6-item questionnaire that assesses daytime and nighttime asthma symptoms, rescue medication use, and the effect of asthma on daily functioning over the previous 4 weeks. Scores range from 0 to 6 , with lower scores indicating better control. The ACQ can be assessed as a continuous variable or dichotomized at 0.75 , which is the level that differentiates controlled from uncontrolled asthma according to the National Institutes of Health (NIH) National Asthma Education and Prevention Program (NAEPP) guidelines. $^{24}$ The ACQ was assessed at 1, 6, and 12 months, after adjustment for baseline ACQ, age, sex, BMI, asthma severity, presence of atopy, baseline predicted FEV1\%, and years of asthma.

Additional secondary outcome measures included FENO, predicted FEV1\%, oral corticosteroid courses, and healthcare utilization (defined as emergency department (ED), hospital, or unscheduled physician visits due to asthma). A research assistant blinded to participant group assignment performed all primary and secondary outcome assessments.

\section{Statistical Analysis}

The primary endpoint of the study was the mAQLQ, a standardized questionnaire with a maximum score of 7.0. With a two-sided type I error rate of 0.05 and a withinsubject standard deviation of 0.9 , as reported previously, ${ }^{25}$ study completion by 58 participants $(29$ participants per arm) would provide $80 \%$ power to detect a difference between groups of 0.75 .

Univariate analyses were first performed using a $t$-test to observe for differences between the groups for all outcomes. Because of a nonlinear trend in mAQLQ and ACQ scores, separate analyses were conducted at each outcome time point. Using linear regression, associations between mAQLQ (and domains) or ACQ scores and group assignment were explored after controlling for each of the baseline covariates (baseline mALQ or ACQ score, age, sex, race, BMI, asthma severity, presence of atopy, baseline predicted FEV1\%, and years of asthma). The outcomes ACQ dichotomized at 0.75 , oral steroid courses, and healthcare utilization were treated as dichotomous variables. For all regression models, covariates that were significant at the 0.20 level during univariate analysis were modeled together. Backward elimination with a cutoff value of 0.05 was used to obtain the final model. All analyses were performed using SAS version 9.2 (SAS Institute, Inc., Cary, NC).

\section{RESULTS}

\section{Patients}

One hundred eighty-one potential subjects were evaluated, and 129 were deemed eligible for participation; 59 refused, and 70 were ultimately enrolled. There were no significant differences in age, race, or sex between those who refused and those who were enrolled. Baseline characteristics of study participants are summarized in Table 1 . The groups were similarly matched for all characteristics $(P \geq .05$ for all comparisons), although there were more women in the control group, and mAQLQ was slightly higher in the intervention group. The control group had slightly greater healthcare utilization than the intervention group, but this was not statistically significant. Average BMI was high for both groups, indicating that many participants were significantly overweight or obese. Figure 1 shows the number of subjects completing each time point. At the end of the 1-year trial, 63 subjects $(90 \%)$ were available for analysis.

\section{Primary Endpoint: Asthma QoL}

As shown in Figure 2, the mean mAQLQ score was significantly higher in the intervention group than in the control group at 1, 6, and 12 months. The magnitude of difference between the two groups decreased over time, although even at 12 months, the difference remained statistically significant. To control for possible confounding effects (including baseline mAQLQ score), a linear regression model was calculated at each time point. As shown in Supplementary Table S3, a statistically significant difference in mAQLQ

\begin{tabular}{|c|c|c|}
\hline Clinical Characteristic & $\begin{array}{l}\text { Intervention } \\
\text { Group, } n=34\end{array}$ & $\begin{array}{c}\text { Control Group, } \\
n=36\end{array}$ \\
\hline Age, mean $\pm S D$ & $72.8 \pm 5.6$ & $73.8 \pm 6.9$ \\
\hline Female, n (\%) & $23(67.6)$ & $31(86.1)$ \\
\hline Years with asthma, mean \pm SD & $25.3 \pm 21.5$ & $31.6 \pm 22.7$ \\
\hline Caucasian, n (\%) & 27 (79.4) & $29(80.6)$ \\
\hline \multicolumn{3}{|l|}{ Asthma severity, $\mathrm{n}(\%)$} \\
\hline Mild persistent & $12(35.3)$ & $13(36.1)$ \\
\hline Moderate persistent & $16(47.1)$ & $19(52.8)$ \\
\hline Severe persistent & $7(20.6)$ & $4(11.1)$ \\
\hline $\begin{array}{l}\text { Body mass index, } \mathrm{kg} / \mathrm{m}^{2} \text {, } \\
\text { mean } \pm \mathrm{SD}\end{array}$ & $29.3 \pm 5.0$ & $30.1 \pm 6.3$ \\
\hline Atopy, $\mathrm{n}(\%)^{\mathrm{a}}$ & $27(79.4)$ & $27(75.0)$ \\
\hline $\begin{array}{l}\text { Percentage of predicted forced } \\
\text { expiratory volume in } 1 \text { second, } \\
\text { mean } \pm S D\end{array}$ & $84.2 \pm 27.4$ & $80.9 \pm 23.6$ \\
\hline $\begin{array}{l}\text { Fraction of exhaled nitric oxide, } \\
\text { mean } \pm \text { SD }\end{array}$ & $31.7 \pm 28.1$ & $30.2 \pm 24.2$ \\
\hline $\begin{array}{l}\text { Mini-Asthma Quality of Life } \\
\text { questionnaire, mean } \pm \text { SD }\end{array}$ & $5.82 \pm 0.92$ & $5.52 \pm 0.94$ \\
\hline $\begin{array}{l}\text { Asthma Control Questionnaire, } \\
\text { mean } \pm \text { SD }\end{array}$ & $1.14 \pm 0.74$ & $1.29 \pm 0.90$ \\
\hline $\begin{array}{l}\text { Hospitalizations in prior } 6 \\
\text { months, } \mathrm{n}(\%)\end{array}$ & $3(8.8)$ & $4(11.1)$ \\
\hline $\begin{array}{l}\text { Emergency department visits } \\
\text { in prior } 6 \text { months, } \mathrm{n}(\%)\end{array}$ & $1(2.9)$ & $2(5.6)$ \\
\hline $\begin{array}{l}\text { Unscheduled visits in prior } 6 \\
\text { months, } n(\%)\end{array}$ & $6(17.6)$ & $13(36.1)$ \\
\hline
\end{tabular}

No significant differences were noted between intervention and control groups for any variable.

Hospitalizations, emergency department visits, and unscheduled visits indicate the number of subjects in each group who had required this service for asthma in the prior 6 months.

${ }^{a} \geq 1$ positive skin tests.

$\mathrm{SD}=$ standard deviation. 


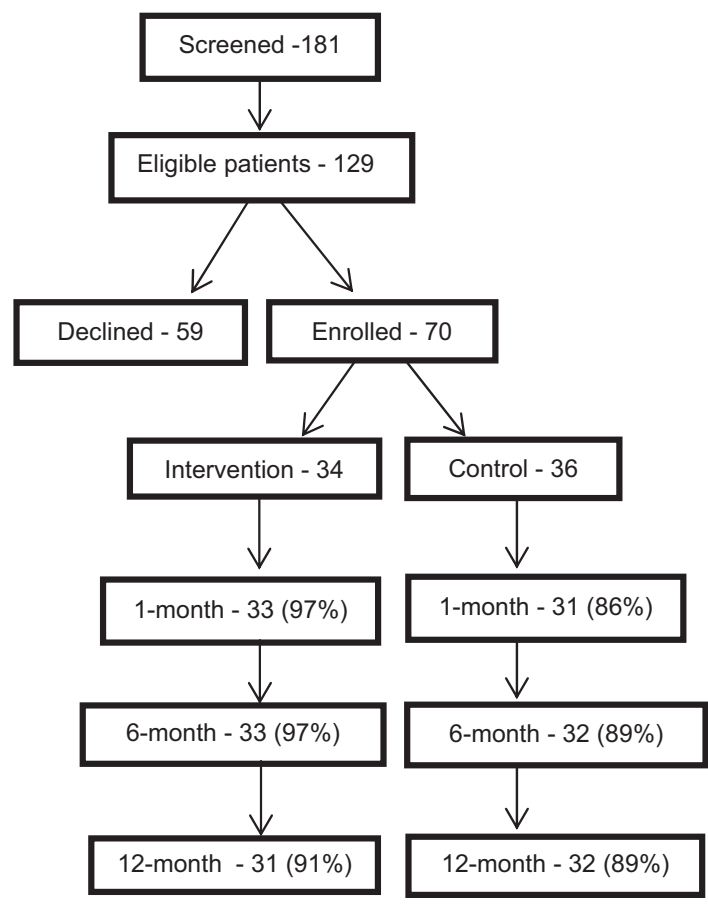

Figure 1. Subject flow diagram.

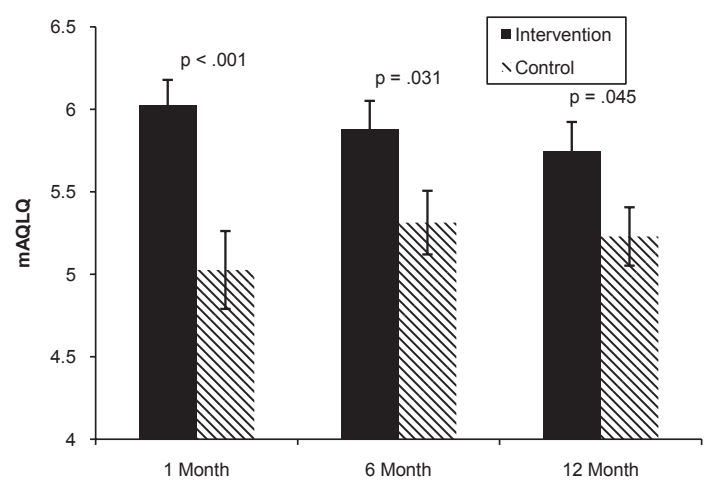

Figure 2. Mini-Asthma Quality of Life scores at 1, 6, and 12 months. Higher scores indicate greater quality of life.

score between the groups was present at 1 and 6 months, although this significance was lost at 12 months.

\section{Secondary Endpoint: Asthma Control}

Mean ACQ score was significantly lower (indicating better control) at 1 month in the intervention group than in the control group and was lower at the 6- $(P=.06)$ and 12-month $(P=.07)$ time points as well. As with the mAQLQ, the magnitude of difference between the two groups decreased over time (Figure 3). The ACQ was dichotomized at 0.75 to assess asthma control further. At 1 month, intervention group participants were 3.8 times as likely to have an ACQ score less than 0.75 as those control group participants $(95 \%$ confidence interval $(\mathrm{CI})=1.15-12.5, P=.03)$. A significant difference was not observed at 6 months, but at 12 months, intervention group participants were 4.2 times as likely to have an ACQ score less than 0.75 as those control group participants $(95 \% \mathrm{CI}=1.14-15.1, P=.03$ ).

To control for possible confounding effects (including baseline ACQ score), a linear regression model was calcu-

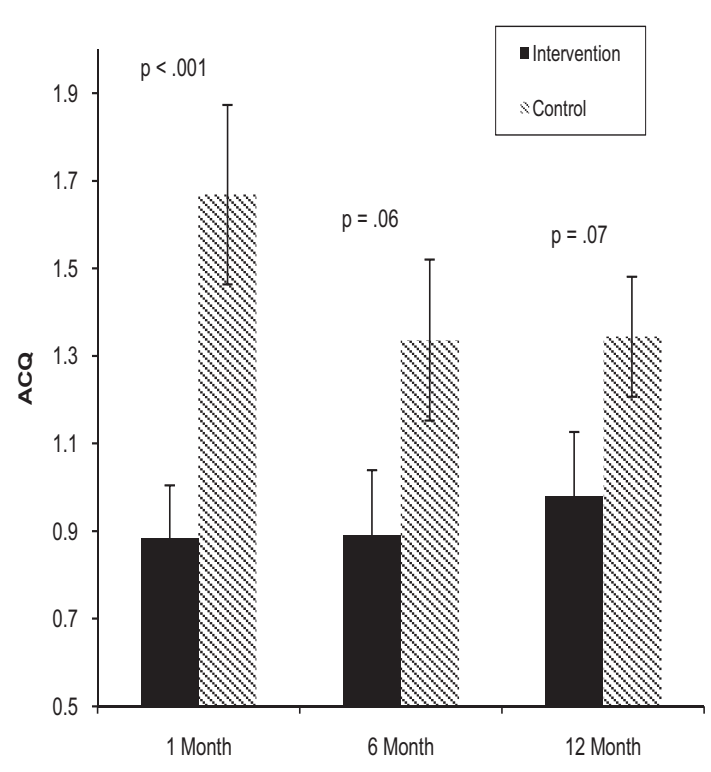

Figure 3. Asthma Control Questionnaire scores at 1, 6, and 12 months. Lower scores indicate greater asthma control.

lated at each time point. As shown in Table S3, ACQ score was significantly lower at 1 and 6 months, although this significance was lost at 12 months.

\section{Additional Secondary Endpoints}

The specific AQLQ domain scores of the intervention and control groups at 1, 6, and 12 months were compared. As shown in Table 2, the greatest difference was observed in the activity domain (significantly higher at all three time points), although others such as the symptom and environmental domains were statistically significantly different as well.

Lung function parameters (predicted FEV1\% and FENO) were evaluated at 6 and 12 months. No difference was seen in FENO, but predicted FEV1\% favored the intervention group at 6 and 12 months $(P=.09)$. Healthcare utilization statistics were evaluated at 6 and 12 months. There was no statistically significant difference in hospitalizations or ED visits between the intervention and control groups, although both favored the intervention group. At 6 months, the number of subjects who had required an unscheduled visit for asthma were lower in the intervention group; at 12 months, unscheduled visits and hospitalizations were lower in the intervention group. When a composite healthcare utilization index (hospitalization, ED visit, or unscheduled visit) was calculated, the intervention group had significantly fewer visits than the control group at 6 and 12 months ( $P \leq .01$ for both). At 12 months, the absolute risk reduction was $32 \%$ for healthcare utilization, and the number needed to treat to prevent one additional event was 3.1. Regression models that included baseline healthcare utilization information were calculated. As shown in Table S3, unscheduled visits and overall healthcare utilization continued to remain significant at the 6 - but not the 12-month visit.

\section{DISCUSSION}

This preliminary study demonstrates that a self-regulation intervention is effective for improving asthma QoL, 


\begin{tabular}{|c|c|c|c|}
\hline Outcome Measure & $\begin{array}{l}\text { Intervention } \\
\text { Group, } \mathrm{n}=\mathbf{3 4}\end{array}$ & $\begin{array}{c}\text { Control Group, } \\
\quad n=36\end{array}$ & P-Value \\
\hline \multicolumn{4}{|c|}{ Asthma Quality of Life questionnaire score, mean } \\
\hline \multicolumn{4}{|c|}{ Symptoms } \\
\hline 1 month & 5.935 & 4.961 & .001 \\
\hline 6 months & 5.794 & 5.269 & .07 \\
\hline 12 months & 5.592 & 5.356 & .37 \\
\hline \multicolumn{4}{|l|}{ Emotional } \\
\hline 1 month & 6.086 & 5.688 & .27 \\
\hline 6 months & 6.091 & 5.813 & .38 \\
\hline 12 months & 6.011 & 5.427 & .07 \\
\hline \multicolumn{4}{|l|}{ Activity } \\
\hline 1 month & 6.283 & 5.202 & .002 \\
\hline 6 months & 6.265 & 5.516 & .02 \\
\hline 12 months & 6.097 & 5.352 & .04 \\
\hline \multicolumn{4}{|l|}{ Environmental } \\
\hline 1 month & 5.768 & 4.237 & .001 \\
\hline 6 months & 5.303 & 4.615 & 11 \\
\hline 12 months & 5.204 & 4.635 & .18 \\
\hline \multicolumn{4}{|c|}{ Asthma Control Questionnaire score <0.75, n (\%) } \\
\hline 1 month & $16(48.5)$ & $7(22.6)$ & .03 \\
\hline 6 months & $18(54.5)$ & $12(38.7)$ & .21 \\
\hline 12 months & $13(41.9)$ & $5(15.6)$ & .02 \\
\hline \multicolumn{4}{|c|}{ Fraction of exhaled nitric oxide, mean } \\
\hline 6 months & 27.9 & 24.0 & .50 \\
\hline 12 months & 25.9 & 26.6 & .90 \\
\hline \multicolumn{4}{|c|}{ Percentage of predicted forced expiratory volume in 1 second, mean } \\
\hline 6 months & 87.4 & 81.1 & .33 \\
\hline 12 months & 84.6 & 76.3 & .17 \\
\hline \multicolumn{4}{|c|}{ Emergency department visits, $\mathrm{n}(\%)$} \\
\hline 6 months & $1(3.0)$ & $2(6.2)$ & .54 \\
\hline 12 months & $1(3.2)$ & $2(6.2)$ & .58 \\
\hline \multicolumn{4}{|c|}{ Hospitalizations, n (\%) } \\
\hline 6 months & $0(0.0)$ & $3(9.4)$ & .07 \\
\hline 12 months & $0(0.0)$ & $4(12.5)$ & .04 \\
\hline \multicolumn{4}{|c|}{ Unscheduled visits, n (\%) } \\
\hline 6 months & $5(15.1)$ & $12(37.5)$ & .04 \\
\hline 12 months & $6(19.3)$ & $14(42.4)$ & .048 \\
\hline \multicolumn{4}{|c|}{ Healthcare utilization, $\mathrm{n}(\%)$} \\
\hline 6 months & $5(15.1)$ & $14(43.7)$ & .01 \\
\hline 12 months & $6(19.3)$ & $17(51.5)$ & .008 \\
\hline
\end{tabular}

asthma control, and healthcare utilization in older adults. Those who participated in the intervention were approximately four times as likely to achieve asthma control as control subjects, and this effect persisted 1 year after the intervention. Participants in the intervention group were also able to decrease healthcare utilization, particularly unscheduled office visits for asthma.

Older adults with asthma may have different symptoms, spirometric findings, and response to therapy than younger individuals. Research has found that older adults have specific concerns related to comorbidities, polypharmacy, and spousal care that are often not addressed in traditional asthma education and are often not discussed with their physicians. $^{26}$ This self-regulation intervention uses the phases of self-observation, self-judgment, and self-reaction and allows individuals to identify specific problems, barriers, and goals to increase self-efficacy and eventually improve multiple asthma outcomes. Self-regulation interventions have improved outcomes for older adults with heart disease ${ }^{27}$ and medication noncompliance, ${ }^{28}$ and the current study supports its efficacy in asthma.
Individuals with a chronic illness often chose QoL as the one variable they would most like to improve, rather than factors such as biomarkers, healthcare utilization, and even longevity. ${ }^{29}$ This has also been found in individuals with asthma and is particularly true in elderly adults. ${ }^{30,31}$ The intervention successfully improved QoL, and even at 12 months, the difference between the control and intervention groups was greater than the minimally clinically significant difference of 0.5 , although because the difference between the groups decreased over time, a booster telephone call might be required for maximal prolonged benefit. Mood disorders can impair asthma QoL, ${ }^{32}$ and self-regulation interventions can improve depression. ${ }^{33}$ It is therefore possible that the improvement in QoL was due to improved mood for individuals with depression, and this deserves further evaluation.

Although the intervention did not directly target the asthma control items contained in the ACQ, the intervention group had significantly greater improvement than the control group. A benefit of the self-regulation intervention is that participants understand that control of items that physicians typically consider important (e.g., symptom identification, rescue inhaler use) allows participation in activities that the patient deems important (e.g., walking with grandchildren).

There were significantly fewer hospitalizations and unscheduled visits but not ED visits at 12 months in the intervention group. Although the overall numbers for healthcare utilization were low, and this study was not designed or powered for this endpoint, the results are encouraging. A number needed to treat of slightly greater than three indicates that this intervention has the potential to decrease the disparities in asthma health care seen in older adults.

Participants received the format of the intervention particularly well. They noted that the camaraderie of the group sessions, along with the personal attention of the telephone calls, was a desirable mix. They were able to share their asthma experiences, frustrations, and treatment strategies with one another, thereby identifying the commonality and differences of their situation. Because older adults may have limited social interaction opportunities, a group format design may be particularly appealing to this population.

Other studies have examined interventions to improve asthma in elderly adults. One did not find that the addition of a peak flow meter improved asthma care in adults aged 50 and older. ${ }^{34}$ The intervention in the current study used peak flow meters, and perhaps the participants found peak flow monitoring more effective through exploration of the device's ability to improve self-efficacy. Another study found that exercise training was able to improve QoL in older adults with asthma, although the magnitude of change was not as great as in the current study, and the follow-up period was only 3 months. ${ }^{35}$ Exercise can improve self-efficacy in older adults, ${ }^{36}$ which could explain some of the results seen in that study.

There are limitations to this study. This was a singlecenter study, and the population was primarily overweight or obese Caucasian women. Reversibility testing with a bronchodilator was not performed, although the latest NIH NAEPP guidelines specifically state that "chronic asthma may be 
associated with a loss of response to bronchodilators,"24 which is especially true in individuals with longstanding asthma, such as elderly adults. ${ }^{37}$ Mental impairment, a frequent comorbidity in elderly adults, would preclude one's ability to participate in the program. The ability to incorporate a health educator may not be possible for all health systems, and a cost-benefit analysis was not performed. The control group had higher baseline healthcare utilization, and even though the regression analysis accounted for this discrepancy, unmeasured variables may have introduced bias to the study. The intervention group received more contacts than the control group, and nonspecific interaction rather than the content may have improved outcomes.

In conclusion, a self-regulation intervention can address the unique challenges that older adults with asthma face. By targeting a disease from an individual's perspective rather than illness from a physician's perspective, this intervention is ideally suited to improve outcomes in elderly adults. Participation in the program was effective in improving asthma QoL and control, although the benefit was partially lost at 1 year. Further exploration is required to decrease disparities in asthma health care seen in elderly adults.

\section{ACKNOWLEDGMENTS}

Conflict of Interest: The editor in chief has reviewed the conflict of interest checklist provided by the authors and has determined that the authors have no financial or any other kind of personal conflicts with this paper.

Supported by the American Academy of Allergy Asthma and Immunology Gail G. Shapiro Clinical Faculty Research Award to Alan P. Baptist.

Author Contributions: Baptist A.P., Ross J.A., and Clark N.M. designed the study. Baptist A.P., Ross J.A., Yang Y., Song P.X.K., and Clark N.M. conducted data analysis. Baptist A.P., Ross J.A., Yang Y., Song P.X.K., and Clark N.M. interpreted the data. Baptist A.P. and Ross J.A. collected the data. Baptist A.P. drafted the article and coordinated author review. All authors reviewed the manuscript and provided comment. Baptist A.P. had full access to the study data and had final responsibility for the decision to submit the manuscript for publication.

Sponsor's Role: The sponsor had no role in the design, methods, subject recruitment, data collections, analysis, or preparation of paper.

\section{REFERENCES}

1. Braman SS, Kaemmerlen JT, Davis SM. Asthma in the elderly. A comparison between patients with recently acquired and long-standing disease. Am Rev Respir Dis 1991;143:336-340.

2. Burrows B, Barbee RA, Cline MG et al. Characteristics of asthma among elderly adults in a sample of the general population. Chest 1991;100:935-942.

3. Hartert TV, Togias A, Mellen BG et al. Underutilization of controller and rescue medications among older adults with asthma requiring hospital care. J Am Geriatr Soc 2000;48:651-657.

4. Enright P. The diagnosis of asthma in older patients. Exp Lung Res 2005;31(Suppl 1):15-21.

5. Dow L, Fowler L, Phelps L et al. Prevalence of untreated asthma in a population sample of 6000 older adults in Bristol, UK. Thorax 2001;56:472-476.

6. Buie VC, Owings MF, DeFrances CJ et al. National Hospital Discharge Survey: 2006 summary. National Center for Health Statistics. Vital Health Stat 2010;13:168
7. Chotirmall SH, Watts M, Branagan P et al. Diagnosis and management of asthma in older adults. J Am Geriatr Soc 2009;57:901-909.

8. American Lung Association, Epidemiology and Statistics Unit, Research and Health Education Division. Trends in asthma morbidity and mortality. September 2012 [on-line]. Available at http://www.lung.org/finding-cures/ourresearch/epidemiology-and-statistics-rpts.html Accessed November 15, 2012.

9. Moorman JE, Mannino DM. Increasing U.S. asthma mortality rates: Who is really dying? J Asthma 2001;38:65-71.

10. Moorman JE, Rudd RA, Johnson CA et al. National surveillance for asthma-United States, 1980-2004. MMWR Surveill Summ 2007;56:1-54.

11. Hunt LW Jr, Silverstein MD, Reed CE et al. Accuracy of the death certificate in a population-based study of asthmatic patients. JAMA 1993;269:1947-1952.

12. Hanania NA, King MJ, Braman SS et al. Asthma in the elderly: Current understanding and future research needs - a report of a National Institute on Aging (NIA) workshop. J Allergy Clin Immunol 2011;128(3 Suppl):S4-S24.

13. Deykin A, Wechsler ME, Boushey HA et al. Combination therapy with a long-acting beta-agonist and a leukotriene antagonist in moderate asthma. Am J Respir Crit Care Med 2007;175:228-234.

14. Sin DD, Man SF. Low-dose inhaled corticosteroid therapy and risk of emergency department visits for asthma. Arch Intern Med 2002;162:1591-1595.

15. Wood PR, Smith B, O'Donnell L et al. Quantifying asthma symptoms in adults: The Lara Asthma Symptom Scale. J Allergy Clin Immunol 2007;120:1368-1372.

16. Stupka E, deShazo R. Asthma in seniors: Part 1. Evidence for underdiagnosis, undertreatment, and increasing morbidity and mortality. Am J Med 2009;122:6-11.

17. Jones SC, Iverson D, Burns P et al. Asthma and ageing: An end user's perspective - the perception and problems with the management of asthma in the elderly. Clin Exp Allergy 2011;41:471-481.

18. Bandura A. Social cognitive theory of self-regulation. Organ Behav Hum Decis Process 1991;50:248-287.

19. Controlling Your Asthma Patient Education Guide. Northbrook, IL: American College of Chest Physicians, 2004.

20. Straus SE, McAlister FA, Sackett DL et al. The accuracy of patient history, wheezing, and laryngeal measurements in diagnosing obstructive airway disease. CARE-COAD1 Group. Clinical Assessment of the Reliability of the Examination-Chronic Obstructive Airways Disease. JAMA 2000;283:1853-1857.

21. Juniper EF, Guyatt GH, Epstein RS et al. Evaluation of impairment of health related quality of life in asthma: Development of a questionnaire for use in clinical trials. Thorax 1992;47:76-83.

22. Juniper EF, Guyatt GH, Willan A et al. Determining a minimal important change in a disease-specific quality of life questionnaire. J Clin Epidemiol 1994;47:81-87.

23. Juniper EF, O'Byrne PM, Guyatt GH et al. Development and validation of a questionnaire to measure asthma control. Eur Respir J 1999;14:902-907.

24. National Asthma Education and Prevention Program (National Heart Lung and Blood Institute). Third Expert Panel on the Management of Asthma. Guidelines for the Diagnosis and Management of Asthma: Full Report 2007. Bethesda, MD: Department of Health and Human Services, National Heart, Lung, and Blood Institute, National Institutes of Health, 2010.

25. Juniper EF, Buist AS, Cox FM et al. Validation of a standardized version of the Asthma Quality of Life Questionnaire. Chest 1999;115:1265-1270.

26. Baptist AP, Deol BB, Reddy RC et al. Age-specific factors influencing asthma management by older adults. Qual Health Res 2010;20:117-124.

27. Janevic MR, Janz NK, Kaciroti $N$ et al. Exercise self-regulation among older women participating in a heart disease-management intervention. J Women Aging 2010;22:255-272.

28. Kucukarslan SN, Thomas S, Bazzi A et al. Using self-regulation theory to examine patient goals, barriers, and facilitators for taking medication. Patient 2009;2:211-220.

29. Meropol NJ, Egleston BL, Buzaglo JS et al. Cancer patient preferences for quality and length of life. Cancer 2008;113:3459-3466.

30. Juniper EF. Health-related quality of life in asthma. Curr Opin Pulm Med 1999;5:105-110.

31. De Luca d'Alessandro E, Bonacci S, Giraldi G. Aging populations: The health and quality of life of the elderly. Clin Ter 2011;162:e13-e18.

32. Mancuso CA, Sayles W, Allegrante JP. Knowledge, attitude, and self-efficacy in asthma self-management and quality of life. J Asthma 2010;47:883-888.

33. Xiao J, Yao S, Zhu X et al. A prospective study of cognitive emotion regulation strategies and depressive symptoms in patients with essential hypertension. Clin Exp Hypertens 2011;33:63-68.

34. Buist AS, Vollmer WM, Wilson SR et al. A randomized clinical trial of peak flow versus symptom monitoring in older adults with asthma. Am J Respir Crit Care Med 2006;174:1077-1087. 
35. Turner S, Eastwood P, Cook A et al. Improvements in symptoms and quality of life following exercise training in older adults with moderate/severe persistent asthma. Respiration 2011;81:302-310.

36. McAuley E, Mullen SP, Szabo AN et al. Self-regulatory processes and exercise adherence in older adults: Executive function and self-efficacy effects. Am J Prev Med 2011;41:284-290.

37. Kaminska M, Foley S, Maghni K et al. Airway remodeling in subjects with severe asthma with or without chronic persistent airflow obstruction. J Allergy Clin Immunol 2009;124:45-51. e41-44.

\section{SUPPORTING INFORMATION}

Additional Supporting Information may be found in the online version of this article:
Table S1. Sample problem selection.

Table S2. Sample barrier selection.

Table S3. Linear regression model demonstrating the effect of the intervention on AQLQ and ACQ.

Please note: Wiley-Blackwell is not responsible for the content, accuracy, errors, or functionality of any supporting materials supplied by the authors. Any queries (other than missing material) should be directed to the corresponding author for the article. 